\title{
Renal and functional outcomes following cystectomy and neobladder reconstruction
}

\author{
Andrea G. Lantz, MD; M. Eric Saltel, MD, FRCSC; Ilias Cagiannos, MD, FRCSC
}

See related article on page 332 .

\begin{abstract}
Background: Orthotopic reconstruction following cystectomy has evolved in an attempt to restore anatomy and function to as close as possible to the preoperative state. We review the renal and functional outcomes of patients who underwent cystectomy and neobladder reconstruction at our institution.

Methods: Between December 2003 and October 2007, 31 patients underwent cystectomy with Studer neobladder reconstruction at the Ottawa Hospital, Ottawa, Ontario, Canada. Follow-up data were obtained regarding renal function (serum creatinine, $\mu \mathrm{mol} / \mathrm{L}$ ), continence, urinary flow rates and post-void residual (PVR) at 3 , 6 and 12 months after surgery. Change in creatinine from preoperative baseline was calculated and analyzed by student t-test to determine if there was a significant rise in creatinine.

Results: There was a statistically significant increase in creatinine from preoperative baseline, with an average increase of 17.3 $\mu \mathrm{mol} / \mathrm{L}, 21.8 \mu \mathrm{mol} / \mathrm{L}$ and $26.3 \mu \mathrm{mol} / \mathrm{L}$ at 3,6 and 12 months, respectively. Six patients developed hydronephrosis. Excluding patients with hydronephrosis, there continued to be a statistically significant rise in creatinine with an average increase of 11.9 $\mu \mathrm{mol} / \mathrm{L}, 14.7 \mu \mathrm{mol} / \mathrm{L}$ and $19.4 \mu \mathrm{mol} / \mathrm{L}$ at 3, 6 and 12 months, respectively. At 1 year, daytime continence was achieved by $89 \%$ of patients; $70 \%$ were continent at night.

Interpretation: Orthotopic neobladders have excellent functional outcomes with low rates of incontinence, which improved throughout follow-up. A significant proportion of patients developed hydronephrosis, highlighting the need for close follow-up to prevent reversible renal deterioration. Creatinine increased during follow-up irrespective of the development of hydronephrosis, but the clinical significance is unknown.
\end{abstract}

Can Urol Assoc J 2010;4(5):328-331

\section{Résumé}

Contexte : La reconstruction orthotopique après cystectomie est née du désir de ramener les structures anatomiques et la fonction le plus près possible de l'état qui prévalait avant l'intervention. Nous examinons ici les résultats sur le plan rénal et fonctionnel de patients ayant subi une cystectomie et une reconstruction néovésicale à notre établissement.
Méthodologie : Entre décembre 2003 et octobre 2007, 31 patients ont subi une cystectomie avec reconstruction néovésicale selon la technique de Studer à l'Hôpital d'Ottawa, en Ontario (Canada). Les données concernant la fonction rénale (créatinine sérique, $\mu \mathrm{mol} / \mathrm{L})$, la continence, le débit urinaire et le volume résiduel postmictionnel ont été obtenues pendant le suivi 3, 6 et 12 mois après l'intervention. Les variations de la créatinine sérique par rapport aux valeurs préopératoires ont été calculées et analysées par test $t$ afin de déterminer la présence $d$ 'une hausse significative de la créatinine sérique.

Résultats : On a noté une hausse significative du taux de créatinine sérique par rapport aux valeurs de départ (avant l'intervention); la valeur moyenne de la hausse était de $17,3 \mu \mathrm{mol} / \mathrm{L}, 21,8 \mu \mathrm{mol} / \mathrm{L}$ et $26,3 \mu \mathrm{mol} / \mathrm{L}$ après 3,6 et 12 mois, respectivement. Six patients ont présenté une hydronéphrose. Si on exclut les patients ayant signalé une hydronéphrose, on note toujours une hausse significative sur le plan statistique du taux de créatinine, la valeur moyenne de la hausse étant de $11,9 \mu \mathrm{mol} / \mathrm{L}, 14,7 \mu \mathrm{mol} / \mathrm{L}$ et $19,4 \mu \mathrm{mol} / \mathrm{L}$ après 3 , 6 et 12 mois, respectivement. Après 1 an, $89 \%$ des patients étaient continents le jour, et $70 \%$ étaient continents la nuit.

Interprétation : La reconstruction néovésicale orthotopique produit d'excellents résultats fonctionnels démontrés par les faibles taux d'incontinence, qui se sont améliorés pendant le suivi. Une proportion significative de patients a présenté une hydronéphrose, soulignant la nécessité d'effectuer un suivi étroit afin de prévenir toute détérioration réversible de la fonction rénale. Le taux de créatinine a augmenté pendant toute la durée du suivi, en présence ou en l'absence d'hydronéphrose, mais la signification clinique de cette observation reste à établir.

\section{Introduction}

Following cystectomy for bladder cancer, the surgeon and patient must select the most appropriate form of urinary diversion. For many years, the ileal conduit was the most commonly used form of urinary diversion. Since the 1980s, the use of orthotopic neobladder urinary diversion has emerged as an option, eliminating the need for a cutaneous stoma and urostomy appliances. A 2007 consensus conference review by the World Health Organization and the Société Internationale d'Urologie found that orthotopic bladder substitutes had similar or lower rates of morbidity compared with conduit diversion with outstanding outcomes possible in appropriately selected, highly motivated patients. ${ }^{1}$ 
Few publications on urinary diversion provide data on renal function. ${ }^{1}$ Renal function has been found to decline with follow-up in some series of conduit diversions, ${ }^{2,3}$ which may be related to the aging process. There is no evidence that orthotopic continent diversions do worse than conduit diversion with respect to renal function. ${ }^{1,4}$

In the present study, we report the renal and functional outcomes of patients undergoing radical cystectomy for bladder cancer with orthotopic Studer neobladder reconstruction.

\section{Materials and methods}

We conducted a retrospective study of 31 consecutive patients who underwent radical cystectomy for bladder cancer with orthotopic Studer ileal neobladder reconstruction at the Ottawa Hospital between December 2003 and October 2007. Data collection was performed by retrospective chart review. Preoperative information including patient age, sex, comorbid conditions and renal function (serum creatinine, $\mu \mathrm{mol} / \mathrm{L}$ ) was obtained. Follow-up data were obtained at 3, 6 and 12 months after surgery. Information was collected regarding neobladder functional parameters, including day and nighttime incontinence (patient reported pads per day or night-time pad use), urinary flow rates (maximum and mean as measured by uroflowmetry; $\mathrm{cc} / \mathrm{sec}$ ), and post-void residual (PVR) volumes (cc) obtained by Bladder Scan BVI 3000 clinic ultrasonography (Verathon Inc., Bothell, VA). Renal function was assessed by serum creatinine measurements. Change in creatinine from preoperative baseline value was compared as a continuous variable using the student's t-test. The presence or absence of hydronephrosis on routine follow-up computed tomography scans was also recorded.

Daytime incontinence was measured on a numeric scale from 0 to 3. None was 0 to 1 "security" pads per day (PPD) for patients with complete continence or those who experience very mild, infrequent stress incontinence and wear a small liner pad for infrequent episodes of minimal incontinence. Mild incontinence was defined as 1 to 2 PPD; moderate was 3 PPD and severe was greater than 3 PPD. Nighttime incontinence was graded as present or absent.

\section{Results}

Thirty-one patients had cystectomy and Studer neobladder reconstruction between October 2003 and December 2007. Twenty-nine patients were male, 2 female. Ages ranged from 43 to 77 years (mean $60.9 \pm 8$ ). Table 1 summarizes patient comorbidities and pathologic stage of disease.

There were 2 deaths during the study duration. One patient died in the immediate postoperative period and 1 developed a pelvic recurrence and died prior to his 12-month follow-up visit. One patient was diagnosed with mantle cell lymphoma on pelvic lymph node dissection performed at the time of cystectomy and was lost to follow-up.

\section{Renal function}

Mean preoperative creatinine was $96.6 \mu \mathrm{mol} / \mathrm{L}$ (SD 17.7). Creatinine measurements showed a statistically significant increase from preoperative baseline (Table 2a). By 12 months, the average increase in creatinine was $26.3 \mu \mathrm{mol} / \mathrm{L}$. No patients required dialysis.

Six patients developed hydronephrosis. Five cases were due to uretero-intestinal anastomotic stricture, including 1 as a result of postoperative anastomotic leak resulting in a stricture rate of $17.9 \%$. One patient had mild hydronephrosis and a suspected upper tract recurrence with positive cytology, but no lesion found on endoscopic evaluation or biopsy.

Excluding patients with hydronephrosis (Table 2b), there continued to be a rise in creatinine which was statistically significant from 6 months onwards. At 12 months, the increase was $19.4 \mu \mathrm{mol} / \mathrm{L}$.

\section{Neobladder function}

On uroflowmetry, the median maximum flow rate was $16.5 \mathrm{cc} / \mathrm{sec}$ (interquartile range [IQR] $10-26 \mathrm{cc} / \mathrm{sec}$ ) and average flow rate was $7.5 \mathrm{cc} / \mathrm{sec}(\mathrm{IQR} 5-10 \mathrm{cc} / \mathrm{sec})$. Median

\begin{tabular}{ll}
\hline Table 1. Patient characteristics \\
\hline Comorbid conditions & N \\
\hline Hypertension & 12 \\
Hypercholesterolemia & 11 \\
Diabetes mellitus & 2 \\
Coronary artery revascularization & 2 \\
Myocardial infarction & 1 \\
Medical renal disease & 1 \\
Urolithiasis & 1 \\
Recurrent urinary tract infection & 1 \\
Rheumatoid arthritis & 1 \\
Emphysema & 1 \\
Human immunodeficiency virus & 1 \\
Multiple sclerosis & 1 \\
Gout & 1 \\
\hline Pathologic stage & N \\
\hline pT0 & 7 \\
$\quad$ N0 & 6 \\
N1 & 1 \\
pTis N0 & 9 \\
pTa N0 & 1 \\
pT1 N0 & 1 \\
pT2 N0 & 1 \\
pT3 & 4 \\
N0 & 1 \\
N1 & 9 \\
N2 & 4 \\
\hline & 2 \\
\hline
\end{tabular}


Table 2a. Change in creatinine, all patients

\begin{tabular}{llc}
\hline & $\Delta \mathbf{C r}, \boldsymbol{\mu m o l} / \mathbf{L}(\mathbf{9 5} \% \mathbf{C l})$ & $\boldsymbol{p}$ value \\
\hline 3 months & $17.3(3.8,30.7)$ & 0.01 \\
\hline 6 months & $21.8(11.5,32.0)$ & 0.0002 \\
\hline 12 months & $26.3(14.2,38.5)$ & 0.0001 \\
\hline $\mathrm{Cr}=$ creatinine. & & \\
\hline
\end{tabular}

voided volume was 205cc (IQR 137 - 318cc) and PVR was 21.3cc (IQR 7 - 45.6cc).

Table 3 summarizes the rates of postoperative incontinence. About one-third (36\%) of patients had daytime incontinence at 3 months, most of which were mild. This decreased to only $11 \%$ at 1 -year follow-up. Nighttime incontinence was present in $62 \%$ of patients at 3 months and decreased to $30 \%$ at 1 year.

\section{Discussion}

Orothotopic neobladders were designed in an attempt to achieve as close to normal anatomy and function as possible. Continence is one of the advantages of the neobladder over conduit diversion. At 1 year, there were excellent continence rates. Daytime continence was achieved in almost $90 \%$ of patients. Seventy percent of patients were dry at night. This is comparable to other reports which are in the range of $67 \%$ to $100 \%$ for daytime, and nighttime incontinence in the range of $45 \%$ to $65 \%{ }^{1,5-12}$ Continence rates improved throughout follow-up, which was to be expected. It is known that as the neobladder capacity increases over time, continence improves. ${ }^{13}$

Urinary diversion following cystectomy must be safe for the upper urinary tract. Storage of urine in the bowel has not been shown to be inherently damaging to the kidneys; renal deterioration is often due to identifiable and reversible causes, such as uretero-intestinal stricture, high pressure storage and chronic infection with associated renal scarring. ${ }^{14}$ Reports of renal function following cystectomy and Studer neobladder reconstruction are limited. Many studies report on functional outcomes and complications without addressing renal function. . $, 6,8,12^{2}$ Conduit diversion is considered the standard to which orthotopic diversion is compared and has been associated with a decline in renal function in some studies. ${ }^{1,3,15,16}$ One study found a moderate decline in glomerular filtration rate, possibly related to aging. ${ }^{15}$

\begin{tabular}{lcc}
\hline \multicolumn{3}{l}{ Table 2b. Change in creatinine, excluding hydronephrosis } \\
\hline & $\Delta \mathbf{C r}, \boldsymbol{\mu m o l} / \mathbf{L}(\mathbf{9 5} \% \mathbf{C l})$ & $\boldsymbol{p}$ value \\
\hline 3 months & $11.9(-0.8,24.7)$ & 0.06 \\
\hline 6 months & $14.7(5.2,24.2)$ & 0.005 \\
\hline 12 months & $19.4(7.3,31.6)$ & 0.004 \\
\hline$C r=$ creatinine. & &
\end{tabular}

Madersbacher and colleagues ${ }^{3}$ found renal morphologi$\mathrm{cal} /$ functional deterioration in $27 \%$ of patients, while Yang and colleagues ${ }^{16}$ found elevated creatinine in only $10 \%$ of patients all of which were due to identifiable and potentially reversible causes, such as infection, stones and obstruction. The literature regarding renal function is difficult to compare as data regarding preoperative renal function and comorbidities are often lacking and different measurements for renal function are often used.

In our study, we found a statistically significant rise in serum creatinine from preoperative baseline. No patients required dialysis postoperatively, and the clinical significance of this finding is unknown. By 12 months of follow-up, the average increase in creatinine was $26 \mu \mathrm{mol} / \mathrm{L}$. A relatively large number of patients developed hydronephrosis. Five were related to stricture of the distal ureter and another with suspected upper tract recurrence. Our stricture rate was $17.9 \%$; most authors report a lower stricture rate between $1 \%$ to $8.5 \%$ with non-refluxing uretero-intestinal anastomoses. ${ }^{4,6,8,11,13,17,18}$ However, even excluding patients who developed hydronephrosis, there continued to be a statistically significant rise in creatinine with an average increase of $19.4 \mu \mathrm{mol} / \mathrm{L}$ at 12 months. It is unclear what the cause of creatinine rise is in these patients. Possible etiologies are absorption of creatinine from the neobladder mucosa or functional aspects of neobladder formation, such as continence, flow rate, incomplete emptying or ureteral reflux. These require future investigation using objective measures, such as urodynamics, to adequately characterize any relationship that may exist.

\section{Limitations}

As a retrospective analysis, the data were limited to what was routinely collected pre- and postoperatively. Measurement of renal function was limited to serum creatinine which is routinely performed at our institution. Serum creatinine is influenced by patient age, sex and lean body mass. There is also evidence that intestinal segments used for urinary diversion might absorb creatinine from the urine ${ }^{19}$ which may result in falsely elevated serum creatinine measurements. More accurate measurement of renal function (i.e., renal scan, estimated glomerular filtration rate or cystatin C) would be helpful but were unavailable for this retrospective

\begin{tabular}{lccc}
\hline Table 3. Postoperative incontinence \\
\hline & $\begin{array}{c}\mathbf{3} \text { months } \\
\mathbf{n}(\%)\end{array}$ & $\begin{array}{c}\mathbf{6} \text { months } \\
\mathbf{n}(\%)\end{array}$ & $\begin{array}{c}\mathbf{1 2} \text { months n } \\
\text { (\%) }\end{array}$ \\
\hline Daytime- overall & $8(36)$ & $5(18)$ & $3(11)$ \\
\hline Mild & $5(20)$ & $3(11)$ & $1(4)$ \\
\hline Moderate & $1(4)$ & $1(4)$ & $2(7)$ \\
\hline Severe & $3(12)$ & $1(4)$ & $0(0)$ \\
\hline Nighttime & $15(62)$ & $16(57)$ & $8(30)$ \\
\hline
\end{tabular}


study. Incontinence rates in this study were based on patient reported pad use. Some patients may be more tolerable of less frequent pad use than others, which may make these results difficult to generalize to other patients. While limited, the subjective outcome measure of continence as defined by pad use is widely used in the literature. The use of standardized questionnaires could address this issue; however, the retrospective nature of the study did not allow for this as these questionnaires are not used in routine follow-up at our institution.

\section{Conclusion}

Orthotopic Studer neobladder reconstruction following cystectomy for bladder cancer offers the patient an option for a less disfiguring surgery without the need for a cutaneous urostomy appliance, and has excellent postoperative continence rates. There was a statistically significant rise in creatinine from preoperative baseline, but this is of unknown clinical significance as no patients progressed to end-stage renal failure or dialysis. Six patients developed hydronephrosis, most commonly due to uretero-intestinal anastomotic stricture. This is a treatable complication and highlights the importance of routine long-term follow-up for these patients. Rise in serum creatinine was seen, however, even in patients who did not develop hydronephrosis. Given the retrospective nature of this study, a prospective investigation using accurate measurements of renal function and validated functional measures is warranted to further clarify the change in renal function and neobladder function in patients with Studer neobladders.

Department of Surgery, Division of Urology, The Ottawa Hospital - Civic Campus, Ottawa, ON

Competing interests: None declared.

This paper has been peer-reviewed.

\section{References}

1. World Health Organization (WHO) Consensus Conference on Bladder Cancer, Hautmann RE, Abol-Enein H, Hafez K, et al. Urinary diversion. Urology 2007;69(1 Suppl):17-49.

2. Jonsson 0 , Olofsson $G$, Lindholm $E$, et al. Long-time experience with the kock ileal reservoir for continent urinary diversion. Eur Urol 2001;40:632-40.

3. Madersbacher S, Schmidt J, Eberle JM, et al. Long-term outcome of ileal conduit diversion. J Urol 2003; 169:985-90.

4. Thoeny $\mathrm{HC}$, Sonnenschein MJ, Madersbacher S, et al. Is ileal orthotopic bladder substitution with an afferent tubular segment detrimental to the upper urinary tract in the long term? I Urol 2002;168:2030-4; discussion 2034.

5. Miyake H, Furukawa J, Takenaka A, et al. Long-term functional outcomes in patients with various types of orthotopic intestinal neobladder. Int J Urol 2008;15:612-5.

6. Nieuwenhuijzen JA, de Vries RR, Bex A, et al. Urinary diversions after cystectomy: The association of clinical factors, complications and functional results of four different diversions. Eur Urol 2008; $33: 834$ 42; discussion 842-4

7. Lee KS, Montie JE, Dunn RL, et al. Hautmann and studer orthotopic neobladders: A contemporary experience. J Urol 2003;169:2188-91.

8. Houtmann RE, de Petriconi R, Gotffried HW, et al. The ileal neobladder: Complications and functional results in 363 patients after 11 years of followup. J Urol 1999;161:422-7; discussion 427-8.

9. Skolarikos A, Deliveliotis C, Alargof E, et al. Modified ileal neobladder for continent urinary diversion: Functional results after 9 years of experience. J Urol 2004;171 (6 Pt 1):2298-301.

10. Santucci RA, Park $\mathrm{CH}$, Mayo ME, et al. Continence and urodynamic parameters of continent urinary reservoirs: Comparison of gastric, leal, ileocolic, right colon, and sigmoid segments. Urology 1999;54:252-7.

11. Arai Y, Taki Y, Kawase N, et al. Orthotopic ileal neobladder in male patients: Functional outcomes of 66 cases. Int J Urol 1999;6:388-92.

12. Meyer JP, Drake B, Boorer J, et al. A three-centre experience of orthotopic neobladder reconstruction after radical cystectomy: Initial results. BJU Int 2004;94:1317-21.

13. Hautmann RE. Urinary diversion: Ileal conduit to neobladder. J Urol 2003;169:834-42.

14. Fontaine $E$, Leaver $R$, Woodhouse CRJ. The effect of intestinal urinary reservoirs on renal function: a 10-year follow-up. BJU Int 2000;86:195-8.

15. Kristijansson $A$, Baic $M$, Wallin $L$, et al. Renal function up to 16 years after conduit (refluxing or anti-reflux anastomosis) or continent urinary diversion. Br J Urol 1995;76:539-45.

16. Yang WJ, Cho KS, Rha KH, et al. Long-term effects of ileal conduit urinary diversion on upper urinary tract in bladder cancer. Urology 2006;68:324-7.

17. Pantuck AJ, Han KR, Perrotti M, et al. Ureteroenteric anastomosis in continent urinary diversion: Long-term results and complications of direct versus nonrefluxing techniques. J Urol 2000;163:450-5.

18. Studer UE, Zingg EJ. Ileal orthotopic bladder substitutes. what we have learned from 12 years' experience with 200 patients. Urol Clin North Am 1997;24:781-93.

19. Rinnab L, Straub M, Hautmann RE, et al. Postoperative resorptive and excretory capacity of the ileal neobladder. BJU Int 2005:95:1289-92.

Correspondence: Dr. llias Cagiannos, Assistant Professor, Department of Surgery, Division of Urology, University of Ottawa, The Ottawa Hospital - Civic Campus, 1053 Carling Ave., Ottawa, ON K1Y 4E9; icagiannos@ottawahospital.on 


\title{
Functional outcomes after urinary diversion: The importance of long-term assessment
}

\author{
Keith Rourke, MD, FRCSC
}

See related article on page 328 .

$\mathrm{R}$ adical cystectomy (RC) has been used to treat bladder cancer for over 100 years. Over time, therapy has evolved from a strictly ablative approach to one aimed at preserving health-related quality of life (HR-QOL). Orthotopic lower urinary tract (LUT) diversion represents the most recent form of LUT reconstruction after RC. Despite many advances, the optimal form of urinary diversion after cystectomy has yet to be definitively demonstrated. ${ }^{1}$ No randomized controlled trial exists comparing existing forms of urinary diversion and no true consensus has been achieved. This may be related in part to the underlying fact that improved health status does not always translate to a demonstrably better quality of life. ${ }^{2}$ This current article examines both renal and functional outcomes of orthotopic ileal neobladder diversion after RC. ${ }^{3}$ Using a cohort of 31 patients, Lantz and colleagues describe changes in serum creatinine, continence and reservoir emptying 1-year post-continent diversion. A significant rise in serum creatinine from a normal baseline and a $17.9 \%$ rate of uretero-ileal stricture formation were found. Eighty-nine percent of patients developed acceptable daytime continence at 1-year (defined as 0 to 1 pads used per day).

Ultimately, patients with a urinary diversion are at risk of upper urinary tract deterioration. Up to $27 \%$ of patients with ileal conduit diversion develop renal dysfunction that may continue to worsen in a time-dependent manner. These changes may not become obvious for 10 to 20 years after urinary diversion. Detrimental change in renal function may be due to chronic urinary tract infection, ureteral obstruction or high neobladder pressures. This current study demonstrates a $26.3 \mu \mathrm{mol} / \mathrm{L}$ increase in serum creatinine from baseline 1-year after neobladder creation. A significant change occurred with or without the presence of hydronephrosis. The implications of these early findings highlight the need for meticulous long-term assessment of renal function and routine imaging of the upper urinary tract after urinary diversion.

In this study, assessment of continence at 1-year revealed daytime and nighttime continence rates of $89 \%$ and $70 \%$, respectively. Although no standard definition of continence or voiding function exists for patients after orthotopic diversion, these early results are encouraging and consistent with most published reports. After 12 months, it is thought that sphincteric function and full neobladder compliance have been achieved. However, deterioration in continence may occur gradually 5 years after orthotopic diversion. It is thought that sphincteric function may actually deteriorate with age and time. ${ }^{4}$ This further emphasizes the need for long-term assessment even when evaluating voiding function after continent diversion.

When reporting functional outcomes after LUT reconstruction, it is also imperative to consider HR-QOL. It is widely assumed patients undergoing orthotopic diversion enjoy a better HR-QOL than those undergoing ileal conduit diversion. Currently, there is no definitive evidence. ${ }^{1}$ Studying HR-QOL measures in a prospective manner will help determine the ideal form of urinary diversion and further optimize patient outcomes. Implementation of HR-QOL outcomes specific to urology will likely play a large role in the future assessment of all forms of LUTreconstruction.

Ultimately, long-term outcomes after orthotopic continent diversion are important to document any potential adverse change in renal function or urinary continence. If long-term continence is not achieved or is achieved at the expense of renal function, orthotopic diversion may not actually preserve HR-QOL. The ideal form of LUT replacement is still unknown, but with prolonged follow-up the ileal neobladder seems most likely to emerge as the gold standard of urinary diversion after RC.

Associate Professor, Division of Urology, Department of Surgery, University of Alberta, Edmonton, AB

Competing interests: None declared.

This paper has been peer-reviewed.

\section{References}

1. Gerharz EW, Mansson A, Hunt S, et al. Quality of life affer cystectomy and urinary diversion: An evidence based analysis. J Urol 2005;174:1729-36.

2. Lee CT. Quality of life following incontinent cutaneous and orthotopic urinary diversions. Curr Treat Options Oncol 2009; 10:275-86.

3. Lantz AG, Saltel ME, Cagiannos I. Renal and functional outcomes following cystectomy and neobladder reconstruction. Can Urol Assoc J 2010;4:328-31.

4. Madersbacher S, Möhrle K, Burkhard F, et al. Long-term voiding pattern of patients with ileal orthotopic bladder substitutes. J Urol 2002;167:2052-7.

Correspondence: Dr. Keith Rourke, Alberta Urology Institute, Suite 400 Hys Centre, 11010-101 St., Edmonton, AB T5H 4B9; krourke@aburologyinstitute.com 